\title{
Correction to: Treatment of Tardive Dyskinesia: A General Overview with Focus on the Vesicular Monoamine Transporter 2 Inhibitors
}

\author{
Nicki Niemann ${ }^{1} \cdot J_{0 s e p h}$ Jankovic $^{1}$
}

Published online: 10 March 2018

(C) Springer International Publishing AG, part of Springer Nature 2018

\section{Correction to: Drugs \\ https://doi.org/10.1007/s40265-018- \\ 0874-x}

\section{Figure 1}

The dose (mg/day) for Clonazepam which reads:

$80-240$

Should read:

$0.25-4$

\section{Figure 1}

The dose (mg/day) for Gingko biloba which reads:

$0.25-4 * *$

Should read:

$80-400$

\section{Figure 1}

Management of tardive dyskinesia. DRBA dopamine receptor-blocking agent, $G P i$ globus pallidus interna, $T D$ tardive dyskinesia, VMAT2 vesicular monoamine transporter $2 . *$ Similar side effects but may be better tolerated than tetrabenazine. $* * 240 \mathrm{mg} /$ day used in randomized controlled trial

Should read:

Management of tardive dyskinesia. DRBA dopamine receptor-blocking agent, $G P i$ globus pallidus interna, $T D$ tardive dyskinesia. *Deutetrabenazine and valbenazine may be better tolerated than tetrabenazine The original article has been corrected.

The legend, which reads 